\title{
Cultura de auditoria E GOVERNANÇA ILIBERAL: UNIVERSIDADES E A POLÍTICA DA RESPONSABILIZAÇÃ̃O ${ }^{1}$
}

\author{
Cris Shore ${ }^{2}$
}

\begin{abstract}
Resumo
Os imperativos econômicos do neoliberalismo combinados com as tecnologias do Novo Gerenciamento Público forjaram profundas mudanças na organização do local de trabalho em muitas sociedades capitalistas contemporâneas. Práticas

\footnotetext{
${ }^{1}$ Publicado em inglês na Anthropological Theory, Vol. 8(3), 2008, pp.278-298, sob o título Audit culture and Illiberal governance. Universities and the politics of accountability. Uma versão deste artigo foi apresentada inicialmente como palestra no encontro anual da Associação Filadélfia no Centro Tavistock, em Londres, setembro de 2006. Comentários sobre versões anteriores do artigo, por meus colegas Christine Dureau, Julie Park, Susanna Trnka, Veronica Strang, Mark Busse, Phyllis Herda e Maureen Molloy, e por dois pareceristas anônimos da Anthropological Theory, são reconhecidos com gratidão. Quero também agradecer meus colegas do Goldsmiths College de Londres com quem compartilhei e discuti muitos dos processos de auditoria descritos neste artigo. Finalmente, tenho uma dívida de gratidão especial para com Susan Wright pelas muitas conversas que tivemos e os artigos que escrevemos juntos sobre o problema da cultura de auditoria como um fenômeno antropológico e forma de governamentabilidade. 0 Comitê Editorial de Mediações agradece ao autor e à Sage Publications pela autorização para publicar este artigo. Tradução de José Fonseca. Revisão de Cláudia Fonseca e Martha Ramírez-Gálvez.

${ }^{2}$ Professor e Chefe do Departamento de Antropologia; Diretor do Instituto da Europa na Universidade de Auckland, Nova Zelândia. Publicou, dentre outros, Corruption: Anthropological Perspectives (editado com Dieter Haller, 2005). Endereço eletrônico: c.shore@auckland.ac.nz
} 
de cálculo que incluem "indicadores de desempenho" e benchmarking são cada vez mais usados para medir e reformar organizações do setor público e melhorar a produtividade e a conduta de indivíduos em diversas profissões. Esses processos resultaram no desenvolvimento de uma "cultura de auditoria" mais e mais generalizada, que deriva sua legitimidade da sua pretensão de aumentar a transparência e a responsabilização (accountability). Utilizando exemplos do Reino Unido, especialmente a reforma das universidades depois da década de 1990, este artigo busca analisar as origens e difusão desta cultura de auditoria e teorizar suas implicações para a construção de subjetividades acadêmicas. As perguntas que faço são: Como essas tecnologias de auditoria estão remodelando o ambiente de trabalho e quais são os seus efeitos sobre o comportamento (e a subjetividade) dos acadêmicos? 0 que a análise da ascensão do gerencialismo nos diz sobre processos históricos mais amplos de poder e mudança na nossa sociedade? E por que os acadêmicos são aparentemente tão cúmplices nesses processos de auditoria e incapazes de desafiá-los?

Palavras-chave:Accountability. Cultura de auditoria. Tecnologias disciplinares. Governabilidade.

\section{Audit CUlture AND ILIBERAL governanCE: UNIVERSITIES AND THE POLITICS OF ACCOUNTABILITY Abstract}

The economic imperatives of neoliberalism combined with the technologies of New Public Management have wrought profound changes in the organization of the workplace in many contemporary capitalist societies. Calculative practices including "performance indicators" and "benchmarking" are increasingly being used to measure and reform public sector organizations and improve the productivity and conduct of individuals across a range of professions. These processes have resulted in the development of an increasingly pervasive "audit culture", one that derives its legitimacy from its claims to enhance transparency and accountability. Drawing on examples from the UK, particularly the post1990s" reform of universities, this article sets out to analyse the origins and spread of that audit culture and to theorize its implications for the construction of academic subjectivities. The questions I ask are: How are these technologies of audit refashioning the working environment and what effects do they have on behaviour (and subjectivity) of academics? What does the analysis of the rise of 
managerialism tell us about wider historical processes of power and change in our society? And why are academics seemingly so complicit in, and unable to challenge, these audit processes?

Keywords: Accountability. Audit culture. Disciplinary technologies. Governmentality.

Vivemos em um momento de história onde a mudança é tão acelerada que começamos a ver o presente apenas quando ele já está desaparecendo. R.D. Laing A Política da Experiência (1967)

\section{INTRODUÇÃO: MOMENTOS DE HISTÓRIA/ TEORIZANDO O PRESENTE}

afirmação de R.D. Laing citada na epígrafe levanta uma importante questão
epistemológica: Como podemos fazer sentido do "presente" quando estamos
nele e somos parte dele? Como avaliar nosso mundo em rápido movimento quando não há fora dele nenhum ponto arquimediano de referência para nos dar perspectiva ou distância crítica? Encontrar tal ponto de vista teórico não é tarefa fácil. As taxonomias que usamos para estruturar nossas percepções e nos classificarmos são frequentemente para nós as coisas mais opacas e imperceptíveis: como peixes em um aquário, nem sempre podemos ver os contornos do vidro que contém a água na qual nadamos. Além disso, muitas vezes o poder de qualquer ordem política reside exatamente na natureza inquestionada dos sistemas classificatórios que governam nosso pensamento e nossa ação. Como disse Pierre Bourdieu (1977, p. 164), "toda ordem estabelecida tende a produzir... a naturalização de sua própria arbitrariedade". Para Bourdieu, parte do trabalho da ciência social crítica envolve uma batalha contínua para estender os limites de "doxa" (a área de pensamento "fora de dúvida") e retornar a um estado de "heterodoxia" que dá à experiência daqueles que são submetidos ao poder arbitrário o "direito de ser falada publicamente" (BOURDIEU, 1977, p. 159, 170). Aqueles regimes de verdade que governam o presente só podem ser contestados se formos capazes de desorganizar e desnaturalizar a "normalidade". 0 assunto deste artigo - as novas formas de governança hegemônica que estão sendo construídas através de sistemas de auditoria e responsabilização - dá um bom exemplo deste dilema. Meu foco analítico é a ascensão da chamada "cultura de auditoria" e 
seus efeitos sobre as universidades britânicas contemporâneas e, indo além da educação superior, sobre a sociedade de forma mais geral.

\section{O QUe É “Cultura DE AUDitoria”?}

Já foi dito muitas vezes - mesmo antes da virada literária da década de 1980 - que os antropólogos na verdade "inventam" as culturas sobre as quais escrevem (CLIFFORD e MARCUS, 1986; WAGNER, 1975). A "cultura de auditoria" não é exceção: o termo é de origem recente e foi cunhado por sociólogos e antropólogos para descrever não exatamente um tipo de sociedade, lugar ou povo, mas uma condição: ${ }^{3}$ uma condição moldada pelo uso de técnicas e princípios modernos de auditoria financeira, mas em contextos muito distantes do mundo da contabilidade financeira. Em outras palavras, ela se refere a contextos nos quais as técnicas e valores de prestação de contas (accountancy) tornaram-se um princípio organizador central na governança e no gerenciamento de conduta humana - e os novos tipos de relações, hábitos e práticas que isso está criando. ${ }^{4}$

As auditorias são tipicamente associadas a registros financeiros e contabilidade, ou seja, sistemas de administração financeira de rotina destinada a verificar orçamentos e garantir que as organizações respeitem normas e regulamentações administrativas. Por que, então, devemos estar interessados em algo tão prosaico e maçante como um "método de contabilidade"? Uma razão é que pequenas mudanças e rotinizações frequentemente atraem processos de mudança social muito mais profundos. Um caso exemplar é o movimento de "gerenciamento científico" iniciado no final do século 19 pelo engenheiro americano F.W. Taylor. As técnicas "tayloristas" eram destinadas a construir um mecanismo para dirigir a conduta de trabalhadores industriais a fim de melhorar a eficiência e aumentar a capacidade de gerenciamento. Mas a revolução gerencial que isso precipitou teve implicações que foram muito além das linhas de produção

\footnotetext{
${ }^{3}$ Entre as primeiras análises publicadas sobre a auditoria como um sistema cultural emergente, conferir Strathern (1997), Shore e Wright (1999), e colaboradores da coletânea editada por Strathern (2000). Grande parte deste trabalho era de natureza reflexiva e analisava a mudança das condições de trabalho e de pensamento dentro da própria academia.

${ }^{4}$ Nesse aspecto, o artigo também contribui para os debates antropológicos sobre o conceito de "bio-poder" de Foucault (1991) e o seu papel no disciplinamento tanto de indivíduos como de populações inteiras. Para uma descrição e análise mais detalhada do significado de "cultura de auditoria”, ver as contribuições de Strathern (2000).
} 
das fábricas. Como mostrou o filósofo francês Michel Foucault (1977, 1991), as rotinas e práticas disciplinares são os veículos através dos quais os governos buscam incutir novos comportamentos e normas de conduta nas populações que eles controlam.

A disseminação da auditoria revela muito sobre as maneiras como os processos de "neoliberalização" (PECK e TICKELL, 2002) estão reorganizando padrões de vida em sociedades industriais avançadas. ${ }^{5}$ Através dela podemos também vislumbrar algo de muito mais profunda significação histórica: um processo que está remodelando nossas instituições do setor público, modificando ambientes de trabalho e transformando nosso sentido de "nós mesmos". A cultura de auditoria é um fenômeno intimamente ligado àquilo que os teóricos da sociologia chamaram de "sociedade de risco" (BECK et al., 1994) e de "economia política de insegurança" (BECK, 2000, p. 2). 0 aumento do uso de auditorias acontece principalmente por causa de preocupações cada vez maiores com a "garantia de qualidade", o "risco operacional" e a "crise de confiança" que aparentemente afligem hoje a maioria das profissões (ver POWER, 2004). Isso se tornou especialmente evidente no Reino Unido, na Austrália e na Nova Zelândia a partir da década de 1990 com o alastramento do processo de reformas do Novo Gerenciamento Público (NGP) que começou na década de 19806. Vários escândalos envolvendo a falha de agências reguladoras ajudaram a alimentar esta crise de confiança pública na capacidade auto-reguladora das profissões. Esses escândalos incluíram o colapso do Banco Barings em 1995, as derrotas da profissão médica (e seu aparente viés cultural em favor de médicos) reveladas pelas investigações dos assassinatos em série cometidos pelo Dr. Harold Shipman, e os inúmeros casos de abuso infantil que atormentaram a Igreja Católica ao longo das últimas décadas (POWER, 2004, p. 22). Acredita-se que todas essas coisas minaram a confiança nos sistemas tradicionais de regulação voluntária e

\footnotetext{
${ }^{5}$ A influência da cultura de auditoria talvez seja mais visível em setores públicos de Nova Zelândia, Austrália e Reino Unido: todos esses países foram submetidos a grandes reformas neoliberais de desregulamentação e privatização de áreas de governo previamente reguladas de acordo com códigos de conduta profissionais e sistemas informais de cooperação e confiança.

${ }^{6}$ Essas reformas NGP incluíam tipicamente um foco em gerenciamento, avaliação de desempenho e eficiência; a utilização de agências que se relacionam na base de pagamento por uso; 0 uso de quase-mercados e contratação externa para promover a competição; redução de custos; e um estilo de gerenciamento enfatizando metas de produção, contratos de prazo limitado, incentivos monetários e liberdade operacional.
} 
deram origem à pressão para substituir a fraca aderência aos códigos de conduta profissional por regimes mais estritos de auditoria e controle externos (0'NEILL, 2002). Os defensores de uma maior intervenção gerencial rejeitam isso como um mito nostálgico e alegam que a ascensão da auditoria aconteceu porque os cidadãos passaram a exigir mais responsabilidade na prestação de contas (accountability) das burocracias remotas. 0 problema desta interpretação (como vou demonstrar) é que enquanto esses sistemas de auditoria podem ser destinados a restabelecer a confiança pública, eles praticamente não permitem que as vozes dos cidadãos sejam ouvidas em qualquer sentido significativo. Na verdade, como 0'Neill observou nas suas Aulas Reith de 2002 na BBC, as auditorias muitas vezes criam a própria desconfiança que elas devem supostamente diminuir. Como um método de verificação, a auditoria desloca relações informais de confiança e só é necessária quando a prestação de contas "precisa ser formalizada, tornada visível e submetida a validação independente" (POWER, 1994, p. 11). Talvez seja este o motivo mais forte pelo qual uma análise mais rigorosa da disseminação de auditorias se justifique devido à maneira como elas moldam e invadem cada vez mais nossas vidas e relações enquanto trabalhadores e profissionais.

\section{A ASCENSÃo DA AUDiTORIA E SUAS CONSEQÜÊNCIAS}

A idéia de auditar surgiu no mundo da regulação financeira. Desde a década de 1990, todavia, ela se espalhou por muitas áreas de vida onde a auditoria como método de verificação nunca existiu (POWER, 1997). Por exemplo, além das auditorias financeiras e auditorias de empresas, agora nós temos "auditorias ambientais", "auditorias de administração de lixo", "auditorias de computador", "auditorias de ensino", "auditorias clínicas e perinatais", "auditorias de democracia", "auditorias de recursos hídricos e fundiários", "auditorias de gerenciamento de riscos de tríplice restrição e lucros" - e até mesmo "auditorias de estresse" e "auditorias de sistemas de auditoria". As auditorias estão sendo usadas para medir e monitorar virtualmente todos os aspectos da vida social e profissional. Parece que, em todos os lugares, brotaram instituições com nomes como "Agência de Garantia de Qualidade", "Agência Nacional de Normas" e "Escritório Nacional de Excelência” encarregadas de avaliar tudo, desde a provisão de saúde pública e 0 ensino universitário até a qualidade do ar urbano e os padrões de dados usados pelo Fundo Monetário Internacional (IMF, 2003). Mas auditar é uma atividade (cada vez mais comercializada) que consome muito tempo e dinheiro e que também está sujeita à lógica da racionalidade econômica. Assim, ela também é caracterizada 
por uma incessante busca de eficiência e economia, que está levando a sistemas cada vez mais elaborados e custo-eficientes para avaliar - e regular - a conduta e o desempenho profissional. Embora as primeiras auditorias exigissem equipes de inspetores que faziam visitas caras, a nova abordagem de "toque mais leve" agora exige que as organizações se examinem e se policiem a si próprias, num sistema às vezes chamado de "auto-regulação regulada". Esse fetiche por medição quantitativa não está limitada ao local de trabalho: por toda a Inglaterra e o País de Gales as crianças de escola agora são submetidas a números sem precedentes de testes compulsórios de capacidade aos 4, 7, 9 e 11 anos de idade e acima disso. A preparação de alunos para estes testes agora norteia a prática em sala de aula, consome uma proporção cada vez maior do tempo dos professores e distorce 0 currículo (GILL, 2004, p. 114).

Uma característica fundamental do processo de auditoria é que ele transforma efetivamente os ambientes nos quais é introduzido - muitas vezes com consequiências imprevistas e desastrosas. Michael Power, um professor de contabilidade na Escola de Economia de Londres, foi o primeiro estudioso a analisar seriamente este fenômeno. Como ele observou há mais de uma década:

a disseminação de auditorias e outras iniciativas de garantia de qualidade significa que muitos indivíduos e organizações agora se acham submetidos a auditoria pela primeira vez e, apesar dos protestos e reclamações, passam a se ver como auditados. Certamente há um sentido real no qual a Inglaterra da década de 1990 tornou-se uma "sociedade de auditoria" (POWER, 1994, p. 1).

Estamos familiarizados com a descrição da Inglaterra como uma "sociedade de classe", uma "sociedade de consumo" e uma "sociedade de risco", mas uma "sociedade de auditoria" é algo novo. 0 que Power afirma é que a auditoria muda a maneira como as pessoas se percebem: ela as incentiva a se medirem a elas próprias e suas qualidades pessoais contra "pontos de referência", "indicadores de desempenho" " "níveis" externos usados pelo processo de auditoria. Uma sociedade de auditoria é aquela em que as pessoas são interpoladas como auditadas, na qual a prestação de contas é mesclada com elaborados mecanismos de controle para submeter o desempenho individual ao olhar de especialistas externos, e na qual todo aspecto de trabalho deve ser classificado e avaliado em relação a metas econômicas e pontos de referência burocráticos. Este é outro forte motivo pelo qual a ascensão da cultura de auditoria na academia e em outros lugares merece atenção; cada vez mais ela molda nossas vidas, nossas relações, nossas identidades profissionais e a maneira como nos conduzimos. 
Por toda a Inglaterra e além dela, essas tecnologias de auditoria estão sendo usadas para reformar e modernizar instituições do setor público ${ }^{7}$. A explicação oficial para isto parece benigna e incontestável: melhorar a eficiência e a transparência e tornar essas instituições mais responsáveis pela prestação de contas ao contribuinte e ao público (e nenhuma pessoa razoável poderia desafiar seriamente objetivos tão sensatos e progressistas). 0 problema, no entanto, é que a auditoria confunde "responsabilidade" (accountability) com "contabilidade" $\left(\right.$ accountancy $^{8}$ de forma que o "ter de responder à cobrança do público" é remodelado em termos de medidas de produtividade, "eficiência econômica" e garantia de "valor por dinheiro". Estes se tornaram os novos princípios de gerenciamento e reforma do setor público - e 0 instrumento de medir pelo qual a responsabilidade de prestar contas deve ser avaliada. Eles são os mesmos princípios que foram usados, desde a década de 1980, para dirigir os "programas de reajuste estrutural" do FMI e do Banco Mundial - políticas que acadêmicos e ONGs criticaram muitas vezes por sua obsessão ideológica com privatização e liberalização e por seus efeitos prejudiciais para os países em desenvolvimento (GRAY, 1998).

As universidades são apenas um local entre muitos outros onde podemos observar os efeitos do neoliberalismo e a ascensão do "Novo Gerenciamento Público". o que testemunhamos aqui é a transformação da idéia liberal e iluminista tradicional, da universidade como um lugar de altos estudos, na idéia moderna da universidade como corporação empresarial cujo interesse primário é a parceria com o mercado: atender as necessidades do comércio, maximizar investimentos e retornos econômicos e obter vantagem competitiva na "Economia do Conhecimento Global". Vários fatores estão dirigindo este processo: 0 regime fiscal de "racionalismo econômico" redutor de custos em que as verbas governamentais para universidades são insignificantes; a mudança de educação universitária de "elite" para educação de "massa", que trouxe muito mais

\footnotetext{
${ }^{7}$ Para perspectivas antropológicas sobre a política de responsabilidade (accountability) e reforma universitária em diferentes países, ver Brenneis, Shore e Wright (2005).

${ }^{8}$ Estes fenômenos são muito diferentes: contabilidade (accountancy) refere-se à "profissão ou os deveres de um contabilista", ao passo que responsabilização (accountability) é um conceito muito mais amplo que se refere à "obrigação que têm os representantes de dar satisfação aos representados sobre a disposição de seus poderes e deveres, agir diante das críticas ou exigências a eles feitas, e aceitar (alguma) responsabilidade por fracasso, incompetência, ou fraude" (Oxford English Dictionary; Concise Oxford Dictionary of Politics).
} 
estudantes sem nenhum aumento comparável no número de pessoal permanente; e a tendência de universidades funcionarem cada vez mais como empresas privadas, acompanhada da emergência da educação superior como uma indústria de exportação significativa (NEW ZEALAND GOVERNMENT, 2001). Auditorias, indicadores de desempenho, exercícios de comparação competitiva, ranking de universidades, gerenciamento por metas, exercícios punitivos de classificação de pesquisa e avaliações periódicas da qualidade de ensino são as tecnologias que foram usadas para disseminar os métodos de novo gerenciamento público na governança de universidades - e tudo no momento em que o orçamento geral do governo para as universidades e por aluno diminuiu.

Os efeitos sociais e psicológicos dessas técnicas e práticas sobre organizações e indivíduos não devem ser subestimados (DEEM, 2004; SPARKES, 2007). Eles incluem um aumento substancial de carga de trabalho e de doenças relacionadas ao estresse ${ }^{9}$. As estratégias de gerenciamento voltadas à criação de uma força de trabalho mais flexível resultaram num grande aumento do número de pessoal docente temporário com contrato de curto prazo que agora executam muitas das funções de ensino e aplicação de exames anteriormente executadas por pessoal permanente e com estabilidade - tudo isso por uma fração do custo, já que nenhum componente de pesquisa está incluído nas suas condições de trabalho. Como descreveu Susan DiGiacomo (2005, p. 58):

Cada vez mais, os departamentos são compostos por docentes contratados por um ano, um semestre ou um curso (para os quais o pagamento é abusivamente baixo). Muitos profissionais plenamente qualificados, com CVs competitivos, são forçados a passar toda a sua vida profissional nesta zona de penumbra, onde nunca recebem nem mesmo a oportunidade de encaminhar um processo de estabilidade funcional. No entanto, como uma condição para a possibilidade de continuarem empregados, eles são obrigados por aqueles que os contratam a demonstrar constantemente um nível de produtividade acadêmica tão alto quanto o de seus colegas com emprego estável, cuja própria atividade acadêmica é monitorada e reavaliada regularmente e que, evidentemente, já internalizaram completamente a necessidade de tal vigilância mesmo em um campo de jogo reconhecidamente desigual.

Junto com o exército de reserva de profissionais marginal e ocasionalmente

\footnotetext{
${ }^{9}$ Segundo uma pesquisa da Associação de Professores Universitários (AUT,Association of University Teachers) a carga horária média semanal de um professor universitário é de 53.5 horas, e um quarto deles tiveram ausências justificadas nos últimos 12 meses por motivo de estresse (AUT, 1998, p. 1).
} 
empregados, a cultura de auditoria também alimentou o crescimento de um regime de burocratas, inspetores, comissionados, reguladores e especialistas que, de acordo com Cooper (2001), está ameaçando nosso sistema de governo e as liberdades democráticas. Será que é este realmente o caso? Alguns alegariam que não há nada de novo nos avisos sobre o perigo criado pelo governo para os direitos civis ou sobre a excessiva intervenção do Estado. Como já dizia o anarquista francês Pierre-Joseph Proudhon dois séculos atrás:

Ser governado é ser vigiado, inspecionado, espionado, dirigido, conduzido pela lei, numerado, regulado, matriculado, doutrinado, alvo de sermões, controlado, verificado, medido, avaliado, censurado, comandado; tudo por criaturas que não têm nem o direito nem a sabedoria nem a virtude para fazer isso. (PROUDHON, 1923 [1851], p. 293) ${ }^{10}$

No entanto, eu acho que a "cultura de auditoria" anuncia algo qualitativa e quantitativamente diferente do tradicional exercício do poder estatal - e talvez também mais preocupante. Em parte, isso se deve à maneira insidiosa com que ela envolve a todos nós em suas redes de poder: seja na forma de verificações anuais de desempenho, exercícios de avaliação de pesquisa, ou na classificação competitiva de nossas instituições nas tabelas de excelência internacional do Suplemento de Educação Superior do The Times (The Times Higher Education Supplement), todos nós caímos na teia da cultura de auditoria, permitindo que ela moldasse nosso modo de pensar e nossas subjetividades. Em uma recente conferência na Austrália, um diretor de universidade lamentou comigo, "me pego falando coisas como 'melhoramento continuado', 'performance e 'outcomes' embora eu odeie essa fala de gerente". A maneira sedutora e sutil com que os conceitos e terminologias gerenciais acabaram se integrando à linguagem acadêmica do diaa-dia é uma outra dimensão deste processo que merece reflexão. Como escreveu Michael Power (1994, p. 41):

\footnotetext{
${ }^{10} 0$ ensaio do Proudhon "0 que é Governo?" continua: "Ser governado é ser a cada operação, a cada transação, notado, registrado, contado, taxado, carimbado, medido, numerado, avaliado, licenciado, autorizado, advertido, prevenido, proibido, reformado, corrigido, punido. É, sob pretexto de utilidade pública, e em nome do interesse geral, ser colocado à disposição, treinado, tosquiado, explorado, monopolizado, extorquido, espremido, enganado, roubado; então, à menor resistência, à primeira palavra de queixa, ser reprimido, multado, vilipendiado, incomodado, acossado, abusado, espancado, desarmado, atado, sufocado, enjaulado, julgado, condenado, fuzilado, deportado, sacrificado, vendido, traído; e para coroar tudo, injuriado, ridicularizado, escarnecido, ultrajado, desonrado. Isto é governo; isto é justiça; isto é moralidade." (Proudhon, 1923 [1851], p. 293-4).
} 
Aparentemente perdemos a capacidade de questionar ou demonstrar publicamente ceticismo sobre a moda de garantir a qualidade: parecem ser soluções naturais para os problemas que enfrentamos - mas será que não são parte do problema?

Meu argumento é que esses novos sistemas de auditoria não são, como alegam, apenas práticas neutras e politicamente inocentes destinadas a promover "transparência" ou eficiência. Ao contrário, são tecnologias disciplinares - ou "técnicas do self" - destinadas a instilar novas normas de conduta na força de trabalho (FOUCAULT, 1977; 1980; ROSE, 1999) ${ }^{11}$. Michel Foucault (1977) mostrou como isto era feito no século XIX quando os imperativos da sociedade industrial e da produção em massa exigiam uma força de trabalho disciplinada e regimentada, que se submetesse livremente às monótonas rotinas das cadeias de produção das fábricas. Mas se "corpos dóceis" eram os "sujeitos" ideais para uma economia baseada em princípios tayloristas de produção em massa, minha pergunta é: Que tipos de "subjetividade" ou "self" são necessários hoje para a "economia do conhecimento global" caracterizada pelo capitalismo rápido e a especialização flexível?

A pesquisa de Emily Martin (1997) sobre treinamento gerencial e liderança nas principais corporações americanas sugere uma resposta possível: 0 trabalhador "flexível", ativo, "auto-administrado" e "auto-disciplinado" que vive num estado de constante reorganização e permanente insegurança será provavelmente muito mais produtivo e custo-eficiente do ponto de vista gerencial. Essas qualidades foram representadas em um cartaz que apareceu nas estações de metrô de Londres em 2000 anunciando os empregos de nível executivo a serem encontrados nas páginas do jornal Daily Telegraph (Figura 1).

\author{
Mais Horas de Trabalho. Mais Estresse. \\ Pressão Maior. Candidate-se Abaixo. \\ Arquivo Negócios Telegraph: \\ Quintas \& Domingos
}

Oportunidades excepcionais. Ambientes dinâmicos. Orientado ao lucro. Pista rápida. Papel central. Pensadores estratégicos. Nível graduado. Multidisciplinar. Alto gabarito. Fortes comunicadores. Progresso rápido. Ar empreendedor. Experiência. Solucionadores de problemas. Habilidades motivacionais. Abordagem proativa. Orientados a resultados. Prêmios consideráveis. Excelentes benefícios.

Arquivo Negócios Telegraph.

Figura 1. Poster no metrô de Londres (2000) anunciando empregos no Arquivo Negócios Telegraph.

${ }^{11}$ Deem e Brehony (2005) chegam a conclusões semelhantes. 
A lista de adjetivos e a celebração machista de "mais estresse" e "pressão maior" refletem as qualidades desejadas e o perfil característico deste novo self corporativo. Mas, como Martin conclui, o gerente corporativo moderno ideal apresenta de fato muitas das qualidades associadas ao Transtorno do Déficit de Atenção (TDA): um senso exagerado de urgência quando envolvido numa tarefa; sempre mudando; facilmente frustrado; entediado por rotinas; tendência ao risco; forte senso de individualismo - em uma palavra, automotivado (ou mais exatamente, "movido a resultados" e "proativo"). As técnicas de governança promovidas pelo novo gerenciamento público são voltadas a produzir trabalhadores de "self flexível" - que não precisam ser supervisionados, mas que "se governam" pelo exercício da introspecção, do cálculo e do discernimento razoável (ROSE e MILLER, 1992). Uma característica fundamental da governança neoliberal é que ela depende de formas mais indiretas de intervenção e controle. Especialmente, ela procura agir sobre e através de agência, interesses, desejos e motivações de indivíduos, incentivando-os a considerarem-se sujeitos ativos responsáveis pelo aprimoramento de sua própria conduta (BURCHELL et al., 1991; ROSE, 1999) ${ }^{12}$. Internalizando as normas externas de gerenciamento, "trabalhadores flexibilizados" transformam-se em súditos governáveis do poder e controle gerencial. Isto não é para sugerir algum tipo de "conspiração global" em andamento: ao contrário, esses processos refletem a lógica do liberalismo econômico atrelada às tecnologias da burocracia moderna. 0 resultado final, no entanto, é uma nova "racionalidade de governança" que converte as pessoas em simples unidades calculáveis de recurso econômico. Em nenhum outro lugar este processo é mais impressionante do que nas reformas administrativas que foram introduzidas no sistema de educação britânico ao longo das últimas duas décadas ${ }^{13}$.

\footnotetext{
${ }^{12}$ Como diz Larner (2000, p. 246), "0 objetivo dessas tecnologias é nos encorajar a exercer nossa agênciamento (agency) e transformar nosso próprio status e administrar nossos próprios riscos”. Ver também a análise de Larner e Le Heron (2003) sobre a neoliberalização de universidades em Nova Zelândia e outros lugares.

${ }^{13}$ Para análises do modo como o novo gerencialismo está alterando as universidades no Reino Unido, ver também Deem (2004); Deem e Brehony (2005); Hey (2001); Shore e Wright (2000).
} 


\section{A INGLATERRA COMO SOCIEDADE DE AUDITORIA: TIRANDO A MEDIDA DAS UNIVERSIDADES}

Deixem-me dar alguns exemplos empíricos de como a difusão da auditoria está reformulando a vida profissional na Inglaterra. Em 2001, logo antes do último Exercício de Avaliação de Pesquisa (RAE - Research Assessment Excercise) ${ }^{14}$, eu fui convocado, como chefe de departamento em uma universidade de Londres, ao gabinete do pró-reitor de Pesquisa. 0 pró-reitor estava preocupado com a possibilidade de não conseguirmos manter 0 grau 5 obtido no último RAE. Diante dele havia uma lista de todos os membros do departamento e os livros e artigos que eles haviam publicado durante 0 período de avaliação (um impressionante total de 26 livros por um grupo complementar de 13 professores). Mesmo assim, cada indivíduo tinha também um conceito diante do seu nome: 5, 4, 4, 5-estrela e assim por diante. Dois deles (de duas professoras, ambas seniores e orientadoras de alunos de graduação) estavam classificados como "3bs". "Então o que vamos fazer a respeito da rabeira?" ele me perguntou. "Você se dá conta que se cair para 4, você perderá \&86,000. Isto equivale a dois postos acadêmicos". Fui informado que eu poderia ou "dar uma licença sabática a X e Y no próximo semestre" para que elas pudessem "publicar aquele livro", ou então simplesmente não relacioná-las no relatório para o RAE, em cujo caso elas seriam estigmatizadas como "inativas em pesquisa" (e estariam potencialmente em quebra de contrato, já que 40\% do salário acadêmico é nominalmente destinado à pesquisa e excelência acadêmica). 0 que aprendi naquele dia foi que o RAE não classifica apenas departamentos, mas cada indivíduo; que os graus distribuídos não levam em consideração as circunstâncias pessoais (como doença, luto ou problemas familiares), e que os departamentos tinham "rabeiras" que eram consideradas uma inconveniência e precisavam ser escondidas ou removidas ${ }^{15}$.

\footnotetext{
${ }^{14}$ O RAE, introduzido em 1986, foi concebido por Sir Peter Swinnerton-Dyer. Ele envolve uma série de exercícios conduzidos nacionalmente para avaliar a qualidade da pesquisa do Reino Unido que é usada para informar como as agências financiadoras do ensino superior no Reino Unido alocam verbas públicas para pesquisa. Esses exercícios visam fornecer perfis qualitativos para pesquisa em todas as disciplinas. As solicitações de instituições são avaliadas por especialistas em cerca de 70 unidades de avaliação que atribuem uma classificação numérica para cada departamento. Os resultados então são publicados pelas agências financiadoras em tabelas de classificação nacional de pesquisa comparativa por excelência (ver RAE, 2001, 2008).

${ }^{15}$ Nesta universidade específica, a alta administração também tentou usar a classificação do RAE para dispensar cerca de 20 acadêmicos "inativos em pesquisa" (mulheres em sua quase totalidade) por quebra de contrato.
} 
Essas observações foram confirmadas no ano seguinte, quando a Universidade de Birmingham anunciou em junho de 2002 que seu Departamento de Sociologia e Estudos Culturais seria fechado no final de julho. Isto foi um choque, não apenas para o pessoal do departamento, mas para a comunidade acadêmica em geral. Por que o novo vice-reitor e a equipe administrativa da Universidade de Birmingham tinham decidido fechar um de seus departamentos de maior sucesso e prestígio internacional - geralmente considerado uma das jóias de sua coroa? Certamente não por razões financeiras: 0 departamento estava economicamente forte com 250 alunos de pesquisa em graduação e 50 em pós-graduação e, aguardava para o semestre seguinte a chegada de mais 30 , principalmente estudantes de pesquisa estrangeiros, pagando altas anuidades (algo com que a maioria dos departamentos universitários podem apenas sonhar). Nem por sua má reputação: o departamento orgulhava-se de sua história e gozava de enorme prestígio internacional enquanto fundador dos modernos Estudos Culturais. Tampouco por causa de má qualidade de ensino ou baixa moral dos professores: 0 departamento acabava de receber a nota máxima de 24 na última Avaliação de Qualidade de Ensino e seu corpo docente era composto principalmente por professores e estudiosos jovens e altamente motivados (BODEN e EPSTEIN, 2002, p. 14). A resposta era por causa do "desempenho" do departamento no Exercício de Avaliação de Pesquisa de 2001. A nova equipe de administração tinha decretado no seu planejamento estratégico que qualquer conceito abaixo de 4 era inaceitável. Desta forma, membros do departamento foram convidados a se desligar voluntariamente ou enfrentar a ameaça de demissão compulsória.

Minha segunda história diz respeito ao ex-direitor de uma escola primária no sul da Inglaterra que cumpriu três meses de prisão por falsificar centenas de testes de avaliação escolar de segundo nível dos seus alunos. Esses testes nacionais de avaliação para todas as crianças nos seus diferentes níveis de educação primária foram projetados em parte para identificar as boas e más escolas. Os resultados são publicados nacionalmente para que os pais possam escolher, com base nesses indicadores de desempenho, a melhor escola para seus filhos. Maus resultados levarão à perda de alunos e à perda de verbas educativas, e podem desencadear uma espiral decrescente que traz "medidas especiais", ou até fechamento. A defesa disse ao tribunal que o diretor sentia-se sob pressão da publicação das listas de classificação e das dificuldades financeiras da escola ${ }^{16}$. No entanto, o juiz considerou seu crime "tão sério" que exigia uma sentença imediata de três meses

${ }^{16}$ BBC News at Ten, 7 de março de 2003. 
de custódia cautelar. Na sua conclusão, ele disse à corte: "Se outros viessem a agir desta maneira o sistema inteiro seria imediata e irremediavelmente destruído, e não se pode deixar que isso aconteça". Mas, em um sistema que exige "conceitos mais altos" e que recompensa chefes executivos "altamente motivados" e "orientados a resultados" é lógico presumir que diretores de escola possam se sentir encorajados a trapacear desta maneira - e é claro, outros também trapacearam ${ }^{17}$.

Meu terceiro exemplo também se refere às metas de desempenho e educação. Em agosto de 2006, os resultados dos exames "nível-A" e "GCES" (certificação geral de ensino secundário) para a Inglaterra foram anunciados. Como de costume, os jornais do país deram a notícia e muitos deles construíram tabelas de classificação comparando o desempenho geral de diferentes escolas nos exames. Os resultados mostraram que as notas gerais do nível-A tinham melhorado em relação ao ano anterior - pelo $22^{\circ}$ ano consecutivo no caso do nível-A. Os resultados do GCES também tinham melhorado ano a ano desde a introdução do GCES em 1988. No entanto, em 2006 o índice de aprovação subiu bruscamente ao nível sem precedentes de 98,1\%, levando comentaristas a descrevê-lo como "0 exame em que é quase impossível ser reprovado" (LIGHTF00T, 2006). De sua parte, as autoridades examinadoras foram categóricas ao afirmar que a aprovação no exame não tinha se tornado mais fácil e insistiram que os padrões foram mantidos. A explicação para a subida, segundo o Diretor de Qualidade e Padrões do Edexcel, um dos três grupos examinadores na Inglaterra, foi basicamente "porque mais alunos estavam fazendo cursos compatíveis com suas habilidades" 18 . No entanto, como de costume, as escolas com resultados muito fracos foram apontadas como fracassos. A política de nomear e envergonhar instituições reprovadas tornou-se um ritual anual nacional de humilhação. A lógica do sistema exige que tabelas de classificação "exponham" as escolas que estão tendo um mau desempenho; isto ocasiona a perda de reputação da escola que rapidamente se traduz em queda de matrícula já que os pais (ou as famílias de classe média que têm condições de fazê-lo) mandam suas crianças para outro lugar. Isso tende a provocar resultados ainda mais fracos no ano seguinte, e então uma espiral de declínio é desencadeada até chegar ao ponto em que se exigem "medidas especiais", tais como a nomeação

\footnotetext{
${ }^{17}$ Em maio de 2003 um diretor de escola de Reading foi repreendido pelo Conselho Geral de Ensino por permitir que os alunos colassem nos testes de avaliação de ciências e matemática. Dois dias antes, diretores de escola tinham considerado boicotar os testes primários e secundários nacionais e exigido a abolição dos exames para crianças de sete anos de idade (Guardian 7 de maio de 2003).

${ }^{18}$ Jim Dobson, Diretor de Qualidade e Padrões do Edexcel, citado em Lightfoot (2006, p. 22).
} 
de um novo "super diretor" ou até mesmo o fechamento da escola.

As tabelas de classificação são ferramentas especialmente insidiosas da cultura de auditoria e fazem parte daquilo que Stephen Ball chama de "gerenciamento como tecnologia moral" (BALL, 1990). Agora há tabelas de classificação para cirurgias em hospitais, serviços de ambulância, respostas às chamadas ao corpo de bombeiros, detenções policiais, pontualidade de trens, cânceres cervicais, fraude de benefícios, ocupação de quadras, limpeza de praia, arrecadação de aluguel e eficiência de câmaras de vereadores. Até os ministérios do governo agora são classificados de acordo com critérios gerenciais de "liderança", "estratégia" e "alcance de metas de serviço público"19. Tudo isso é de origem recente. A idéia de tabelas de classificação para escolas e hospitais foi introduzida no início da década de 1990 pelo governo Conservador, que viu nisso uma maneira de aumentar a produtividade e realocar recursos. A justificativa para essas tabelas foi que elas "empoderam" pais e contribuintes (agora definidos como clientes e consumidores) fornecendo a eles a informação necessária para fazer escolhas racionais no seu consumo de "mercadorias" educacionais e de saúde. Ao reduzir tudo a simples e claras contagens matemáticas, essas medições possibilitam a comensurabilidade entre todas as áreas de escolas e entre os sujeitos. Assim, o desempenho de todo aluno, professor ou instituto pode agora ser quantificado, calibrado, comparado, escrutinizado, visibilizado, classificado, premiado ou punido - tudo em nome do "aumento de qualidade". Não interessa que as condições entre instituições possam diferir: a tabela de classificação fornece uma grade que posiciona todos e cada um. Como no modelo da prisão panóptica de Jeremy Bentham, o sistema é simultaneamente "individualizador e totalizador" (FOUCAULT, 1977).

Essas contagens numéricas ou classificações por estrelas geralmente têm pouco a ver com "qualidade" como esta é entendida pela maioria dos profissionais $^{20}$, mas como qualquer diretor de escola ou vice-reitor sabe, a publicação delas pode promover ou destruir uma carreira. Não surpreende que elas tenham transformado a atmosfera de toda instituição pública na Inglaterra. Nas escolas primárias e secundárias, esta obsessão com classificações leva a

\footnotetext{
${ }^{19}$ Jill Sherman, The Times, 6 de junho de 2003, p. 14.

${ }^{20}$ A maioria dos acadêmicos que entrevistei para minha pesquisa atual sobre reforma universitária desdenharam a idéia de que a qualidade de pesquisa pode ser medida por contagens numéricas, ou pelo "fator de impacto" de uma revista acadêmica. Muitos também mostraram como essas medidas de fator de impacto e número de citações podem ser manipulados e distorcidos.
} 
um cuidado sem precedentes com 40-50\% dos alunos mais bem posicionados, enquanto os últimos classificados em nível de habilidade somem de vista - ou podem até ser desencorajados a prestar exames nos quais eles podem receber conceitos D ou E. Como resume Simon Jenkins (1996, p. 20): "os resultados precisam ser padronizados e estatisticamente revigorados. A questão deve ser 'certo ou errado', múltipla escolha, modular e tabular, em vez de escrita ou dissertativa. 0 discernimento profissional deve ser minimizado. 0 burocrata deve estar no comando". 0 problema é que a quantificação distorce os atributos daquilo que alega medir. 0 que essas estatísticas demonstram é apenas até que ponto as "metas" foram atingidas. Em suma, as estatísticas e as tabelas de classificação são os instrumentos através dos quais um novo regime de gerenciamento está sendo imposto, regime este que transforma as tecnologias de auditoria na própria arte de governar.

\section{A ASCENSÃo dA CULTURA DE AUDITORIA NA INGLATERRA: UMA BREVE HISTÓRIA}

Os últimos anos testemunharam um crescimento surpreendente na idéia de auditoria e na confiança em sua capacidade de garantir efetividade e eficiência em todas as áreas de trabalho. Um efeito disto foi transformar auditoria e regulação em uma das profissões que mais crescem hoje no Reino Unido. Ao contrário de outras áreas do setor público que estão encolhendo, o aparato regulatório do Estado está florescendo. Em 1997, quando os Conservadores deixaram o poder, havia "150 agências reguladoras, ombudsmen, inspetorias e monitorias empregando umas 20.000 pessoas e custando cerca de 1 bilhão de libras esterlinas para funcionar" (CAULKIN, 2002). Desde 1997, este aparato ficou ainda maior. Recentemente, The Economist identificou 600 novas metas às quais o setor público está agora submetido, desde tempo de espera em hospitais até níveis de alfabetização e índice de eliminação de criminalidade (CAULKIN, 2002). Para tudo isso tem de haver internamente coleta e medição de números que depois são auditados externamente. Firmas de auditoria como KPMG, Ernst and Young, e Pricewaterhouse Cooper enriqueceram nas costas de um mercado garantido pelo Estado. No Reino Unido hoje, mais de 600.000 companhias limitadas, além de hospitais, universidades, autoridades locais, fundos de pensão, escolas, sindicatos, associações habitacionais e filantrópicas precisam ter suas declarações financeiras auditadas por contadores profissionalmente qualificados. Embora a 
missão dessas firmas internacionais de auditoria seja promover a responsabilidade (accountability), a transparência e a "boa governança", muitas conduzem seus próprios negócios internos de formas que estão longe de ser transparentes ou de dar satisfação ao público (accountable) (MITCHELL e SIKKA, 2002). De fato, as quatro maiores firmas comerciais que dominam o negócio da contabilidade internacional estão todas "sediadas em paraísos fiscais e sem tratados de troca de informação com outros países" (COUSINS et al., 2004, p. 4). Essas firmas gostam de projetar uma imagem de "esteios de integridade" protegendo os ideais do serviço público. Isto pode explicar em parte por que os acadêmicos aceitam tão prontamente a sua autoridade. A realidade, no entanto, é que essas firmas de auditoria são corporações financeiras privadas cuja razão de ser é a busca do lucro - um mandato sancionado pela lei que sobrepuja qualquer pretensão sobre responsabilidade social corporativa. Como Joel Bakan (2004, p. 55) nos lembra, a corporação moderna é uma instituição definida por "cobiça e indiferença moral".

Tudo isso leva a perguntar "como chegamos a esse ponto?" A ascensão da cultura de auditoria na Inglaterra pode ser rastreada até as reformas do governo Thatcher de 1979, que buscou reduzir o gasto público, "diminuir o estado" e aumentar a eficiência dos servidores públicos submetendo-os às estimulantes disciplinas do mercado. Os ministros insistiam que o setor privado era efetivamente regulado por mecanismos de mercado e, portanto este modelo devia ser aplicado ao setor público. Aumentar a eficiência significava invariavelmente corte de gastos e medidas para transformar instituições públicas em pseudonegócios. 0 Decreto Financeiro de Governo Local de 1982, introduzido por Michael Heseltine, foi o primeiro passo para disciplinar as Autoridades Locais. Nos departamentos governamentais os funcionários públicos sofreram cortes de 14\% ao longo de cinco anos, limites de verba foram impostos à maioria das atividades do serviço público, e cada departamento foi organizado como um "centro de custos" com indicadores de desempenho para seu trabalho e objetivos pessoais anuais para cada indivíduo. Por trás dessas iniciativas econômicas havia uma agenda política. Segundo Collini (2003, p. 7) foi um "assalto calculado por governos Tory às instituições que eles consideravam dispendiosas, autocentradas, arrogantes e liberais". Foi também uma tentativa de impor a disciplina dos mercados e o Novo Gerenciamento Público às profissões e, nesse processo, reclassificar funcionários mais como "unidades de trabalho a serem incentivadas e mensuradas" do que como "pessoas a serem encorajadas e desenvolvidas".

Para garantir obediência, o governo criou a "Comissão de Auditoria" - 
uma nova agência reguladora que seria, em suas próprias palavras, "uma força motriz na melhoria dos serviços públicos" (COMISSÃO DE AUDITORIA, 1984, p. 1). 0 nascimento desta agência marcou o momento-chave na história britânica em que o discurso e as práticas de contabilidade financeira mudaram e se expandiram para incluir o "monitoramento de desempenho" e a identificação da "melhor prática" (1984, p. 3). Auditar não significava mais apenas conferir as contas: agora determinava a definição daquilo que constitui a "boa governança" e a formação da própria política pública.

A Comissão de Auditoria simbolizava a idéia neoliberal de Estado regulador e "governança à distância", insistindo que seus funcionários (muitos dos quais tinham sido temporariamente transferidos de firmas particulares de auditoria como a Coopers \& Lybrand e a Peat Marwick) operassem independentemente dos governos central e locais. Esta demanda de "independência", no entanto, era enganadora, já que toda a renda auferida pela Comissão de Auditoria provinha de taxas cobradas das autoridades locais, e estas autoridades locais estavam obrigadas por lei a pagar a Comissão de Auditoria por inspeções regulares e participação em seus programas de auditagem (AUDIT COMMISSION, 1996, p. 4). A reforma da educação superior seguiu um modelo semelhante. 0 Relatório Jarrettt de 1985 sobre "eficiência" no setor universitário representou a primeira grande mudança no discurso de "para que servem as universidades". Fazendo eco ao clima da nova era, ele argumentava que as "universidades são primeiro e antes de tudo empresas corporativas" e que "a questão crucial é como uma universidade garante valor por dinheiro". A linha do governo era que como as universidades estavam "frustrando a economia" elas eram alvos legítimos de reformas drásticas e controles externos. A solução proposta nas Instruções Normativas do Governo de 1993 foi criar uma "Cultura Empreendedora" dentro das universidades da Inglaterra para tornálas mais enxutas e competitivas (HER MAJESTY'S GOVERMENT - HMG, 1993). Ao mesmo tempo, o plano era dobrar o número de ingresso de estudantes na universidade sem aumentar significativamente a dotação de verbas. Essas reformas constituíram uma importante cisão com a abordagem tradicional do governo de não se imiscuir na administração das universidades - uma prática ligada ao até então sacrossanto princípio de liberdade acadêmica. Para manter a ilusão de nãointerferência, o governo criou uma nova agência financiadora chamada Conselho Financiador da Educação Superior para a Inglaterra (HEFCE). Assim como a Comissão de Auditoria, este conselho devia supostamente ser independente do governo, mas na prática serviu de instrumento deste. 
A falta de espaço me impede de detalhar todas as inovações subseqüentes. Basta dizer que o governo (através de suas agências "independentes") introduziu uma grande quantidade de novas medidas destinadas a tornar as universidades mais receptivas às forças do mercado. Tais medidas incluíram a mudança do estatuto legal da estabilidade acadêmica e providências para condicionar 0 financiamento das universidades à consecução de metas governamentais; a introdução de Auditorias de Qualidade Acadêmica e de Ensino para garantir a qualidade dos serviços universitários diante do aumento do número de estudantes e a diminuição de verbas; e o Exercício de Avaliação de Pesquisa introduzido em 1986 para medir e "melhorar" a qualidade de pesquisa na universidade.

Deixando de lado os enormes custos que essas auditorias infligiram às universidades e o aumento da carga de trabalho para um pessoal sobrecarregado, 0 ranking competitivo de departamentos através de tabelas classificatórias de ensino e de pesquisa teve um efeito nocivo sobre o coleguismo (SHORE e WRIGHT, 1999). As informações de colegas tornaram-se base para a aprovação de verbas departamentais pelo HEFCE. Os departamentos com problemas, ao invés de receber apoio, eram punidos com mais cortes de suas verbas. Por volta do início da década de 1990, os acadêmicos britânicos tinham sido completamente envolvidos como auditados e cúmplices em um sistema de auditoria que era ao mesmo tempo punitivo e divisivo. Como disse recentemente um acadêmico aposentado: "[a] horrorosa exaustão moral diária que é o RAE foi com certeza a principal razão da minha aposentadoria... o sistema encorajava ativamente a publicação de lixo, de irrelevâncias, ou do absolutamente óbvio"21 .

\section{COMO A AUDITORIA TRANSFORMA AS ORGANIZAÇÕES - E OS INDIVÍDUOS}

A questão colocada no início foi "como essas tecnologias de auditoria mudaram a cultura universitária e que efeito elas tiveram sobre as organizações e identidades profissionais?". No nível institucional, a auditoria revolucionou a maneira como as universidades britânicas se autodefinem: elas são corporações financeiras transnacionais, com ênfase em gerar renda através de pesquisa comercializada, em treinar ao invés de educar, e em dotar os alunos (agora chamados de "clientes" e "usuários") de capacidades mais vendáveis do que

${ }^{21}$ Ver Sparkes (2007, p. 545).

Cultura de auditoria e Governança ILIBERAL... 
críticas. Os novos regimes de auditoria também precipitaram uma mudança no gerenciamento de universidades, que agora são definidas em termos de suas equipes de gerenciamento e administração. Os acadêmicos não são mais tratados como membros constitutivos da universidade, mas como seus empregados, uma força de trabalho proletária individualizada que deve ser "subordinada à hierarquia organizacional de gerentes, pessoas de quem a 'Universidade' deve exigir excelência"22. Como Bill Readings observou uma década atrás, as universidades se tornaram "líderes de mercado" em marcas de qualidade e na busca de "excelência". No entanto, "a aplicabilidade geral do termo excelência", continua Readings (1996, p. 23), "está em relação direta com o seu caráter vazio".

A revolução da auditoria mudou igualmente a definição dos termos "qualidade" e "padrões". Apesar da ênfase nessas palavras, o significado delas é invariavelmente vago. Algumas universidades buscaram o mundo de negócios para esclarecimento, e adotaram a definição de qualidade do Instituto Britânico de Padrões como "aptidão para um propósito". Mas isto simplesmente leva a uma linha de raciocínio ainda mais circular e convoluta na qual "qualidade" significa "aptidão para um propósito", "aptidão para um propósito" é mensurada em termos de "excelência" e "excelência" é definida em termos de qualidade, e assim por diante.

Ao se preparar para auditoria, a maioria das universidades britânicas criou novos cargos em "garantia de qualidade" e comissões para adequar seus procedimentos aos padrões previstos nas exigências de assessores externos. Uma disciplina inteiramente nova foi criada em torno das oportunidades de carreira oferecidas pela nova indústria de garantia de qualidade. A fim de tornarem-se "auditáveis", todos os departamentos devem apresentar uma longa documentação para que os inspetores possam avaliar se seus "mecanismos de controle interno" e suas estruturas de "garantia de qualidade" são consistentes (ver POWER, 1996). Fazer com que essas estruturas estejam visíveis para escrutínio é um enorme dreno nos recursos da universidade. Cada vez mais, os acadêmicos britânicos projetam suas pesquisas pensando na burocracia da avaliação de qualidade e criam evidência mensurável de desempenho que produzirácontagens positivas no próximo exercício de avaliação. A preparação para a "próxima” TQA (Avaliação de Qualidade de Ensino) ou RAE é hoje o evento mais importante no plano qüinqüenal de toda

\footnotetext{
${ }^{22}$ Essas mudanças em governança - e a relegação do papel do professor - são também características fundamentais da reforma universitária na Nova Zelândia.
} 
universidade. Muitas universidades chegam a fazer ensaios gerais e instruem estudantes e professores sobre o que dizer aos inspetores da TQA (a nova máxima é "conversa imprudente custa dinheiro"). Alguns departamentos teriam inventado atas de reuniões que nunca aconteceram. A própria forma de lidar com as novas medidas de desempenho se tornou, ela mesma, uma "performance" tanto no sentido teatral como sociológico (SHORE e SELWYN, 1998). A auditoria também mudou o conteúdo e o estilo do currículo. Para ser auditada, a "experiência de aprendizado" precisa agora ser quantificada e padronizada de forma que possa ser medida. Os méritos do currículo agora são calculados em termos daquilo que é mais visível ao escrutínio externo: habilidades tangíveis, transferíveis e vendáveis. Para muitos acadêmicos:

Não importa mais realmente se um professor ou uma professora ensina bem ou mal, ou se eles às vezes inspiram seus alunos; é muito mais importante que tenham produzido planos para seus cursos, bibliografias, esboços disso, daquilo e daquilo outro, em suma toda a parafernália de fútil burocratização exigida para assessores que vêm do alto como emissários do castelo de Kafka (JOHNSON, 1994, p. 379).

\section{CONCLUSÃO: CULTURA DE AUDITORIA E SUAS INSATISFAÇÕES}

A história que contei é uma história da contabilidade (accounting) como uma força poderosa na transformação do setor público do Reino Unido. A auditoria foi usada com sucesso para apoiar um regime de novo gerenciamento público que dá pouca ênfase ao profissionalismo e demasiado crédito ao gerencialismo explícito (FITZSIMONS, 2004). Ao levantar estes argumentos não estou procurando elaborar um caso contra a auditoria ou a transparência propriamente ditas. Estou certo de que as auditorias, quando usadas corretamente, podem ser instrumentos muito eficazes para prevenir fraude, má administração e desperdício de dinheiro público. 0 que estou dizendo é que houve uma confusão entre a auditoria como método de verificação financeira e de contadoria, e a auditoria como modelo generalizado (e tecnologia) de governabilidade. As tecnologias de auditoria podem ter conseguido produzir maior economia, obediência e produtividade na força de trabalho, mas no processo elas também mudaram a definição daquilo que constitui o conhecimento legítimo e a melhor prática. Como resume Fredrik Barth: 
0 que é colocado nas mãos deste leviatã burocrático não é nada menos do que 0 poder de substituir e formar os critérios de validade que governam o conhecimento antropológico na Inglaterra: Se os critérios de validade acadêmicos tradicionais não foram totalmente eclipsados, eles certamente serão significativamente suplementados por este regime. (BARTH, 2002, p. 9)

Como tentei argumentar, o conceito gerencialista de accountability é coercitivo e autoritário (SHORE e WRIGHT, 2000); ele também reduz as relações profissionais a moldes crus, quantificáveise passíveis de monitoração (STRATHERN, 1997). Longe de "promover accountability" para com os contribuintes e acionistas, as auditorias tendem a obscurecer a transparência e alimentar a desconfiança. Além disso, enquanto as auditorias alegam ser instrumentos para tornar os profissionais mais sujeitos a prestar contas ao "publico", de fato, a prestação de contas (accountability) é dirigida às agências reguladoras e ao pessoal indicado pelo governo. A centralização do poder do Estado através de auditoria e regulação é um fenômeno que deveria inquietar aqueles que se preocupam com a erosão das liberdades civis.

0 que me alarma é ver até que ponto nós aceitamos tão passiva e acriticamente os argumentos da auditoria. Vale a pena observar que os maiores escândalos de corrupção da história - Enron e WorldCom - ambos envolveram companhias que eram submetidas às formas mais rigorosas de auditoria financeira por uma das firmas mais respeitadas de auditoria global - Arthur Anderson. A nossa fé mal colocada nas técnicas de auditoria e contabilidade está, aparentemente, destruindo as próprias organizações que nos são caras. As universidades têm semelhança apenas superficial e altamente enganadora com empresas comerciais e, como Collini (2003, p. 5) observa, a qualidade da maior parte daquilo que a universidade oferece "pode ser julgada, mas não pode ser medida". Para lembrar o famoso aforisma de Einstein: "nem tudo que conta pode ser contado, e nem tudo que é contável conta".

0 intrigante nisso tudo é "por que é tão difícil para os acadêmicos desafiar a auditoria?". "Todo acadêmico que conheço", escreveu um dos avaliadores de uma primeira versão deste artigo, "odeia esta tendência, está furioso com as maneiras como ela desvia nossa atenção daquilo que consideramos ser nosso "verdadeiro" trabalho, e distorce este trabalho ao tentar medi-lo de maneiras ridiculamente inadequadas". Como foi que chegamos a permitir que medidas 
quantitativas arbitrárias determinem valor? ${ }^{23}$ Mais importante ainda, como foi que nos tornamos cúmplices em sua operação? Em parte é porque a auditoria parece tão "razoável" que se torna difícil de contestar; quem pode se opor legitimamente a "transparência", ou "qualidade" ou "responsabilidade"? Neste sentido, o novo regime de governamentabilidade engendrado por auditoria e novo gerencialismo é projetado para agir sobre e através de nossas capacidades como profissionais e agentes morais. Os valores aos quais a maioria dos acadêmicos aderem (inclusive auto-disciplina e um desejo de produzir pesquisa de qualidade) tornaram-se assim instrumentais ao provocar conduta aquiescente e governante (BURCHELL et al., 1991; ROSE, 1999). Isto pode também ser parte da razão pela qual a cultura de auditoria é tão difícil de contestar; o ambiente universitário ficou tão atolado em princípios e práticas gerenciais que é difícil encontrar aquele ponto arquimediano fora do sistema que nos possibilita criticá-lo. Como escreveu Bourdieu (1977, p. 189), "[os] efeitos ideológicos mais eficazes são aqueles que não têm necessidade de palavras, e não pedem mais do que o silêncio cúmplice".

A cumplicidade de acadêmicos também nasce do fato de que o sistema só pode ser contestado coletivamente - e há enormes custos e penalidades se indivíduos ou instituições individuais tentarem desafiar ou sair do processo de auditoria. Certamente, o processo de auditoria tornou dispendioso demais para indivíduos e instituições até mesmo admitir problemas ou deficiências, como vimos no exemplo do RAE 2001 e do diretor de escola que falsificou os resultados de testes dos seus alunos. Mas outros fatores além da ameaça de sanções engendram nossa cumplicidade. As forças competitivas estimuladas por esses novos sistemas gerenciais, como Hey (2001) e Ozga (1998) sugerem, são fortemente sedutoras ao recrutarem nosso comportamento por meio de seus mecanismos de recompensa e punição. Alguns acadêmicos se beneficiam claramente dos novos regimes de auditoria, pois eles quebram velhas hierarquias e oferecem novos caminhos para a promoção rápida, pelo menos para o pessoal mais envolvido em pesquisa ou de tendência gerencial ${ }^{24}$. A maioria dos acadêmicos talvez saiba que a fé em auditoria (como a fé no "mercado") não se sustenta na sua eficácia real em fazer

\footnotetext{
${ }^{23}$ Esta é uma questão levantada por um dos acadêmicos do Reino Unido no artigo de Andrew Sparkes (2007, p. 541).

${ }^{24}$ Como disse um professor universitário desiludido, "alguns trabalhadores acadêmicos apreciam (não, adoram) o sistema RAE - eles podem pedir verbas de pesquisa apenas por pedir e demonstrar um desejo ardoroso e fetichista de agradar os planejadores do sistema" (citado em Sparkes, 2007, p. 545).
} 
o que afirma fazer, mas os interesses, carreiras e estruturas que se forjaram como resultado desses sistemas de auditoria criaram para os indivíduos um poderoso desincentivo a balançar o barco publicamente.

Meu argumentoéque a auditorianãoéapenas umasériedepráticas técnicas: ela precisa ser entendida também como uma idéia, um processo e um conjunto de técnicas gerenciais. 0 alastramento da auditoria para diferentes cenários como hospitais, universidades, companhias de água e departamentos do governo não é simplesmente uma resposta óbvia aos problemas de governança e responsabilidade (accountability), antes, é uma questão de política de regulamentação e controle gerencial. Eu também quis fazer uma crítica antropológica sobre o que acontece quando as práticas de auditoria "migram" para áreas às quais nunca tinham sido destinadas. E é com este raciocínio que eu gostaria de terminar: a auditoria tem uma vida própria - uma característica fugidia - que não pode ser controlada ${ }^{25}$. Uma vez introduzida em um novo cenário ou contexto, ela constrói (ou coloniza) ativamente aquele ambiente a fim de torná-lo auditável. Os efeitos são irreversíveis. Um desses efeitos é a perda de espaço para criatividade e iniciativa. Os imperativos do gerenciamento de risco deixam os profissionais com uma sensação cada vez mais forte de que "a gente está se tornando um funcionário em um edifício que apenas quer saber se você cumpriu suas funções específicas, e se as checagens necessárias sobre isto também foram realizadas" (CLAPHAM, 2006, p. 6). Em um recente congresso de psicoterapeutas e psicólogos clínicos (duas profissões que estão sendo viradas pelo avesso por exigências da parte do governo de responsabilidade (accoutability) e certificação conforme os princípios da "medicina baseada em evidências"), um psicoterapeuta resumiu assim o seu dilema:

Agora parece difícil, se não impossível, praticar medicina como um profissional, a não ser movendo-se pelas frestas do mundo governado e auditado clinicamente. Para se ter uma relação profissional com o paciente, na qual exista um contrato, não dito e não assinado, na qual ambas as partes tenham uma responsabilidade... agora é preciso ser um subversivo e desafiar o poder de governo e da governança. (CLAPHAM, 2006, p. 7)

Segundo vários oradores no congresso, os regimes de auditoria e inspeção cada vez mais intrusivos que estão sendo levados adiante pela "aversão ao risco" e o gerencialismo do Serviço Nacional de Saúde geram agendas procedimentais

\footnotetext{
${ }^{25}$ Strathern usa um argumento semelhante ao escrever sobre os "efeitos fugidios deste processo [de auditoria] que começou, por assim dizer, com as metas puras da melhoria educacional" (1997, p. 310).
} 
contraditórias nas quais a "subversão" torna-se a única maneira de um clínico manter sua integridade profissional. Assim como nos setores universitário e educacional, a cultura de auditoria não promoveu transparência ou eficiência organizacional, muito pelo contrário, de fato. Os exemplos etnográficos que utilizei indicam que esses processos de auditoria estão tendo um efeito corrosivo no senso de profissionalismo e autonomia das pessoas. Numa época em que "aversão ao risco" tornou-se um mantra de gerenciamento organizacional moderno, é hora de exigir explicações do gerencialismo e falar publicamente sobre os riscos que a cultura de auditoria agora cria para nossas universidades e profissões públicas.

\section{REFERÊNCIAS}

AUDIT Comission. Audit Commission for England and Wales. Report of Accounts for Year Ended 31 March 1984. London: HMSO, 1984.

. Annual Report and Accounts for Year Ended 31 March 1996. London: HMSO, 1996.

AUT - Association of University Teachers. UpDate, 50. April, 1998.

BAKAN, Joel. The Corporation: The Pathological Pursuit of Profit and Power. London: Constable, 2004.

BALL, Stephen. Management as Moral Technology. In: BALL, Stephen. (ed.) Foucault and Education: Disciplines and Knowledge. London: Routledg, pp. 153-66, 1990.

BARTH, Fredrik. An Anthropology of Knowledge. Current Anthropology 43(1): $1-18,2002$.

BECK, Ulrich. The Brave New World of Work. Cambridge: Polity Press, 2000.

BECK, Ulrich; GIDDENS, Anthony e LASH, Scott. Reflexive Modernization: Politics, Tradition and Aesthetics in the Modern Social Order. Cambridge: Polity Press, 1994.

BODEN, Rebecca e EPSTEIN, Debbie. It All Adds Up To a Pretty Brum Do. The Times Higher Educational Supplement 1556 (September 20): 14, 2002.

BOURDIEU, Pierre. Outline of a Theory of Practice (trad. Richard Nice). Cambridge: Cambridge University Press, 1977.

BRENNEIS, Don; SHORE, Cris e WRIGHT, Susan. Getting the Measure of Academia: 
Universities and the Politics of Accountability. Anthropology in Action 12(1): $1-10,2005$.

BURCHELL, Graham; GORDON, Colin e MILLER, Peter (eds.). The Foucault Effect: Studies in Governmentality. London: Harvester Wheatsheaf, 1991.

CAULKIN, Simon. Too Many Sums Don't Add Up. The Observer 12 May, 2002. URL (acesso 22.11.2006); http://observer.guardian.co.uk/business/ story/0,6903,713834,00.html\#article

CLAPHAM, Miles. The Sarcophagus of Practice. Paper não publicado apresentado naAnnual Conference of the Philadelphia Association: Tavistock Clinic London, 16 de setembro, 2006.

CLIFFORD, James e MARCUS, George (eds). Writing Culture: The Poetics and Politics of Ethnography. Berkeley: University of California Press, 1986.

COLLINI, Stefan. HiEdBiz. London Review of Books 25(21): 3-9, 2003.

COOPER, Andrew. The State of Mind We're. In: Social Anxiety, Governance and the Audit Society. Psychoanalytic Studies 3 (3-4): 349-62, 2001.

COUSINS, Jim; MITCHELL, Austin e SIKKA, Prem. Race to the Bottom: The Case of the Accountancy Firms. Basildon: Association for Accountancy and Business Affairs, 2004.

DEEM, Rosemary. The Knowledge Worker, the Manager-Academic and the Contemporary UK University: New and Old Forms of Public Management? Financial Accountability and Management 20(2): 107-28, 2004.

DEEM, Rosemary e BREHONY, Kevin. Management as Ideology: The Case of "New Managerialism" in Higher Education. Oxford Review of Education 31(2), 2005.

DIGIACOMO, Susan. Audit Culture and the Politics of Accountability: A Comparative Perspective. Anthropolog y in Action 12(1), pp. 57-63, 2005.

FITZSIMONS, Matthew. "Managerialism and the University". New Zealand Journal of Tertiary Education Policy 1(June), pp, 16-18, 2004.

FOUCAULT, Michel. Discipline and Punish: The Birth of the Prison. Harmondsworth: Penguin, 1977.

. Power/Knowledge: Selected Interviews and Other Writings 1972-1977 (edited by Colin Gordon). New York: Pantheon Books, 1980.

. Governmentality. In: BURCHELL, Graham Burchell; GORDON, Colin \& 
MILLER, Peter (eds) The Foucault Effect: Studies in Governmentality. London: Harvester Wheatsheaf, pp. 87-118, 1991.

GILL, Peter. Mathematics. In: WHITE, John. (ed.) Rethinking the School Curriculum: Values, Aims and Purposes. London: Routledge, pp. 104-116, 2004.

GRAY, John. False Dawn: The Delusions of Global Capitalism. London: Granta, 1998.

HEY, Valery. The Construction of Academic Time: Sub/Contracting Academic Labour in Research. Journal of Education Policy 16 (1), pp. 67-84, 2001.

HMG - Her Majesty's Government. Realising Our Potential. A Strategy for Science, Engineering and Technology. London: HMSO, Cm 2250, 1993.

IMF - International Monetary Fund. Data Quality Assessment Framework and Data Quality Program, 2003. (Quinta Revisão das Iniciativas de Padronização de Dados 25 de junho). URL (acessado em 13 de setembro de 2006); http: //www. imf.org/external/np/sta/dsbb/(2003)/eng/dqaf.htm\#I

JENKINS, Simon. In League with Ignorance. The Times 20 de novembro: 20, 1996.

JOHNSON, Neville. Dons in Decline. Twentieth Century British History 5(3), pp. 370-385, 1994.

LAING, Ronald David. The Politics of Experience and the Bird of Paradise. Harmondsworth: Penguin, 1967.

LARNER, Wendy. Post-Welfare State Governance: Towards a Code of Social and Family Responsibility. Social Politics 7(2), pp. 244-65, 2000.

LARNER, Wendy \& LE HERON, Richard. Neoliberalising Universities? Spaces of Policy, Practice and Performance. New Zealand Journal of Sociology 18(2), pp. 102-114, 2003.

LIGHTF00T, Liz. Rise and Rise of the Exam That's Almost Impossible to Fail. Daily Telegraph, 22. 25 de agosto, 2006.

MARTIN, Emily. Managing Americans: Policy and Changes in the Meanings of Work and the Self. In: SHORE, Cris e WRIGHT, Susan. (eds) Anthropology of Policy. London and New York: Routledg, 1997, pp. 239-57.

MITCHELL, Austin \& SIKKA, Prem. Dirty Business: The Unchecked Power of Major Accountancy Firms. Basildon: Association for Accountancy and Business Affairs, 2002. 
NEW ZEALAND GOVERNMENT. Export Education in New Zealand: A Strategic Approach to Developing the Sector. Wellington: Ministry of Education, 2001. URL (acessado em 10 de março 2008); http://www.educationcounts.govt.nz/ publications/international/export_education_in_new_zealand_a_strategic_ approach_to_developing_the_sector_-_an_overview

0'NEILL, Onora. A Question of Trust: The BBC Reith Lectures of 2002. Cambridge: Cambridge University Press, 2002.

OZGA, Jenny. The Entrepreneurial Researcher: Re-formations of Identity in the Research Marketplace. International Studies in Sociology of Education 8(2), pp. 143-153, 1998.

PECK, Jamie \& TICKELL, Adam. The Urbanization of Neoliberalism: Theoretical Debates on Neoliberalizing Space. Antipode 34(3), pp. 380-404, 2002.

POWER, Michael. The Audit Explosion. London: Demos, 1994.

. Making Things Auditable. Accounting, Organizations and Society 21, pp. 289-315, 1996.

The Audit Society: Rituals of Verification. Oxford: Oxford University Press, 1997.

1. The Risk Management of Everything: Rethinking the Politics of Uncertainty. London: Demos, 2004.

PROUDHON, Pierre-Joseph. General Idea of the Revolution in the Nineteenth Century (trans. John Beverley Robinson). London: Freedom Press, 1923 [1851].

RAE URL, 2001. Acessado em 10 de março de 2006: http://www.hero.ac.uk/rae/ , 2006. Acessado em 10 de março de 2006: http: //www.rae.ac.uk

READINGS, Bill. The University in Ruins. Cambridge, MA: Harvard University Press, 1996.

ROSE, Nikolas. Powers of Freedom: Reframing Political Thought. Cambridge: Cambridge University Press, 1999.

ROSE, Nikolas \& MILLER, Peter. Political Power beyond the State: Problematics of Government. British Journal of Sociology 43(2), pp. 173-205, 1992.

SHORE, Cris \& SELWYN, Tom. The Marketisation of Higher Education: Management Discourse and the Politics of Performance. In: JARY, David \& PARKER, Martin (eds). The New Higher Education: Issues and Directions for the Post-Dearing 
University. Stoke on Trent: Staffordshire University Press, pp. 88-95, 1998.

SHORE, Cris \& WRIGHT, Susan. Audit Culture and Anthropology: Neo-Liberalism in British Higher Education. Journal of the Royal Anthropological Institute 5(4), pp. 557-75, 1999.

. Coercive Accountability: The Rise of Audit Culture in Higher Education. In: STRATHERN, Marilyn (ed.). Audit Cultures: Anthropological Studies in Accountability, Ethics and the Academy. (EASA Series). London: Routledge, pp. 57-89, 2000.

SPARKES, Andrew. Embodiment, Academics, and the Audit Culture: A Story Seeking Consideration. Qualitative Research 7(4), pp. 521-50, 2007.

STRATHERN Marilyn. "Improving Ratings": Audit in the British University System. European Review 5(3), pp. 305-21, 1997.

. Introduction: New Accountabilities. In: STRATHERN, Marilyn (ed.). Audit

Cultures: Anthropological Studies in Accountability, Ethics and the Academy. (EASA Series). London: Routledge, pp. 1-18, 2000.

WAGNER, Roy. The Invention of Culture. Englewood Cliffs, NJ: Prentice-Hall, 1975. 